\title{
Single-molecule measurements of viral ssRNA packaging
}

\author{
KALLE J. HANHIJÄRVI, ${ }^{1}$ GABIJA ZIEDAITE, ${ }^{2}$ DENNIS H. BAMFORD, ${ }^{2,3}$ EDWARD H/EGGSTRÖM, ${ }^{1}$ \\ and MINNA M. PORANEN ${ }^{2}$ \\ ${ }^{1}$ Department of Physics, ${ }^{2}$ Department of Biosciences, University of Helsinki, Helsinki 00014, Finland \\ ${ }^{3}$ Institute of Biotechnology, University of Helsinki, Helsinki 00014, Finland
}

\begin{abstract}
Genome packaging of double-stranded RNA (dsRNA) phages has been widely studied using biochemical and molecular biology methods. We adapted the existing in vitro packaging system of one such phage for single-molecule experimentation. To our knowledge, this is the first attempt to study the details of viral RNA packaging using optical tweezers. Pseudomonas phage $\phi 6$ is a dsRNA virus with a tripartite genome. Positive-sense (+) single-stranded RNA (ssRNA) genome precursors are packaged into a preformed procapsid (PC), where negative strands are synthesized. We present single-molecule measurements of the viral ssRNA packaging by the $\phi 6$ PC. Our data show that packaging proceeds intermittently in slow and fast phases, which likely reflects differences in the unfolding of the RNA secondary structures of the ssRNA being packaged. Although the mean packaging velocity was relatively low $(0.07-0.54 \mathrm{~nm} / \mathrm{sec})$, packaging could reach $4.62 \mathrm{~nm} / \mathrm{sec}$ during the fast packaging phase.
\end{abstract}

Keywords: optical tweezers; phage $\phi 6$; RNA packaging; dsRNA virus

\section{INTRODUCTION}

Viral genome encapsidation, an essential step in the viral life cycle, ensures production of new infectious virions. Many DNA viruses, such as herpesvirus, adenovirus, and most DNA bacteriophages, package their genome into a preformed empty protein capsid by a viral molecular motor using energy from NTP hydrolysis (Smith et al. 2001; Baines and Weller 2005; Ostapchuk and Hearing 2005; Fuller et al. 2007a,b; Rickgauer et al. 2008; Sun et al. 2010; Smith 2011; Chemla and Smith 2012; Speir and Johnson 2012) Instead, most RNA viruses utilize an alternative genome encapsidation strategy in which the genome is condensed prior to or during capsid assembly and the capsid is formed around the condensing genome (Pirttimaa and Bamford 2005; Speir and Johnson 2012).

Pseudomonas phage $\phi 6$ (family Cystoviridae) is an unusual RNA virus that packages its genome into a preassembled dodecahedral capsid, the procapsid (PC), in a process analogous to that of many dsDNA phages. The tripartite dsRNA genome ( $\mathrm{S}, \mathrm{M}$, and $\mathrm{L}$ segments [single-stranded segments are written in lower case letters, and double-stranded segments in capitals]) is initially packaged in single-stranded form but is subsequently replicated by viral RNA polymerase inside the PC to form dsRNA genome segments (Fig. 1). As in other dsRNA viruses, such as rotavirus, blue tongue virus,

Corresponding author: kalle.hanhijarvi@helsinki.fi

Article is online at http://www.rnajournal.org/cgi/doi/10.1261/rna. 057471.116. and rice dwarf virus, the dsRNA genome of $\phi 6$ is always replicated and transcribed inside the core particle (Fig. 1) to prevent the potential dsRNA-induced host responses. Therefore, the genome is encapsidated as an ssRNA (Fig. 1).

The PC of $\phi 6$ (a.k.a. polymerase complex or empty core) comprises four proteins: P1, P2, P4, and P7 (Fig. 1). The major coat protein P1forms a dodecahedral skeleton (Olkkonen and Bamford 1987) in which $60 \mathrm{P} 1$ dimers are arranged in a $T=1$ icosahedral lattice (Butcher et al. 1997; Huiskonen et al. 2006). Such organization is also observed in the cores of many eukaryotic dsRNA viruses but not in other viruses (Poranen and Bamford 2012). Approximately 12 copies of the RNA-dependent RNA polymerase P2 reside inside the P1 shell close to its threefold symmetry axes, making connections between the neighboring fivefold vertices that are oriented inward in the empty PC (Nemecek et al. 2010; Sun et al. 2012; Ilca et al. 2015). P2 carries out viral genome replication and transcription (Juuti and Bamford 1995) starting from the beginning of the $3^{\prime}$-end of the template RNA using a primer-independent initiation mechanism (Makeyev and Bamford 2000a,b; Butcher et al. 2001; Wright et al. 2012). P7 functions as an assembly (Poranen et al. 2001) and packaging cofactor (Juuti and Bamford 1995, 1997) and is located

(C) 2016 Hanhijärvi et al. This article is distributed exclusively by the RNA Society for the first 12 months after the full-issue publication date (see http://rnajournal.cshlp.org/site/misc/terms.xhtml). After 12 months, it is available under a Creative Commons License (Attribution-NonCommercial 4.0 International), as described at http://creativecommons.org/licenses/ by-nc/4.0/. 


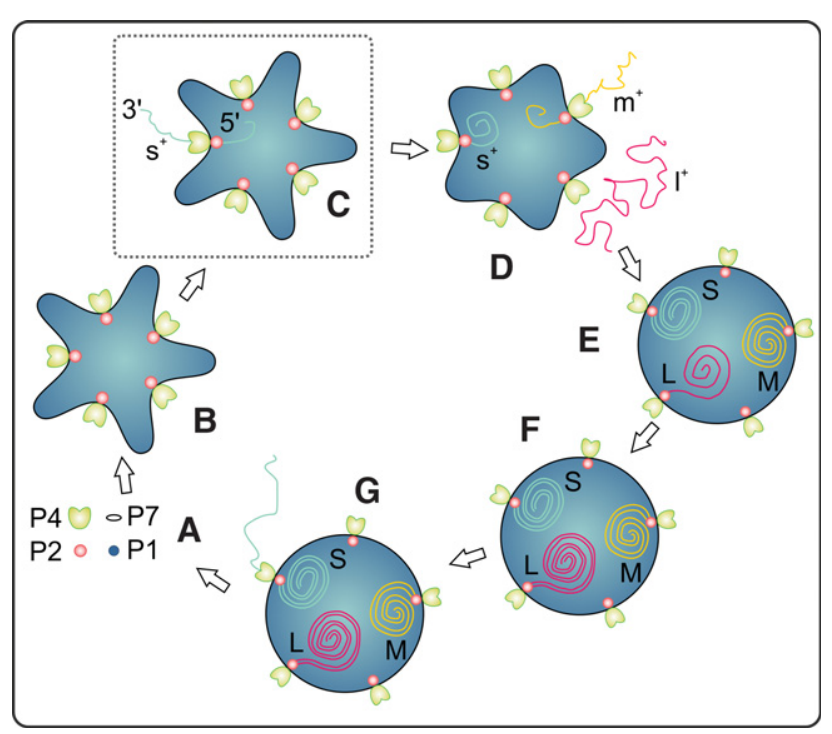

FIGURE 1. Replication cycle of $\phi 6$. Viral proteins are produced within the host $(A)$, and assemble into empty procapsids $(B)$. Plus-sense ssRNAs are packaged into the procapsid by the packaging NTPase P4 in the order $\mathrm{s}^{+}(C), \mathrm{m}^{+}(D)$, and $\mathrm{l}^{+}$simultaneously with procapsid expansion. Minus-sense RNAs are synthesized in the capsid (E), forming the three-segmented dsRNA genome $(F)$. Transcribed plus-sense RNA segments are extruded from the capsid $(G)$, which results in production of new viral proteins. The box indicates the part of the virus life cycle that is relevant to our experiments (packaging of the $\mathrm{s}^{+}$genomic segment onto the empty procapsid in the $5^{\prime}-3^{\prime}$ direction).

within the P1 shell, close to the $\mathrm{P} 2$ positions (Nemecek et al. 2012).

P4 is a hexameric packaging NTPase forming turret-like protrusions at the fivefold vertices of the icosahedrally symmetrical P1 shell (Fig. 1; Butcher et al. 1997; de Haas et al. 1999; Huiskonen et al. 2007). This creates a symmetry mismatch between the sixfold symmetrical P4 turrets and the P1 pentamers at the PC vertices (de Haas et al. 1999), as also observed in the packaging vertex of dsDNA phages (Hendrix 1978; Simpson et al. 2000). P4 has several key functions in the virus replication cycle: It nucleates the PC self-assembly in vitro (Poranen et al. 2001); it is needed for viral RNA transcription (Pirttimaa et al. 2002), possibly by providing a passive conduit for ssRNA extrusion from the PC (Kainov et al. 2004); and it functions as the molecular motor during the packaging of the three ssRNA genome precursor molecules into the PCs (Gottlieb et al. 1992a).

The packaging NTPase of $\phi 6$ belongs to RecA-like ATPases (El Omari et al. 2013). It has five conserved sequence motifs common to hexameric helicases of the superfamily SF4 (Kainov et al. 2003, 2006; Mancini and Tuma 2012) and is also structurally related to these helicases (El Omari et al. 2013). The structure and function of the packaging NTPase P4 hexamers are also well described for the related dsRNA phages $\phi 12$ and $\phi 13$, and high-resolution structures are also available for several other cystoviral NTPases, including the P4 of $\phi 6$ (Kainov et al. 2003, 2008;
Mancini et al. 2004; Lísal et al. 2005; Meier et al. 2005; El Omari et al. 2013). The hexamers are composed of six identical monomers arranged in a ring, resembling a domed toroid around a central channel (Mancini et al. 2004; Meier et al. 2005). The central channel hosts nucleic acid binding sites: the loops L1 and L2, essential for both packaging and helicase activity (Lísal et al. 2005; Kainov et al. 2008). These loops are structurally equivalent to the nucleic acid binding sites of other related hexameric helicases (Mancini and Tuma 2012). The detailed structural, biochemical, and biophysical studies on cystoviral P4 NTPases have resulted in a mechanistic model (Mancini and Tuma 2012) that describes the ssRNA translocation driven by sequential ATP hydrolysis (Kainov et al. 2003, 2008; Mancini et al. 2004; Lísal and Tuma 2005; Lísal et al. 2005).

The ssRNA packaging into the $\$ 6 \mathrm{PC}$ is sequential and precisely controlled. The three precursor genome segments are packaged in order of size $\left(\mathrm{s}^{+}, \mathrm{m}^{+}\right.$, and $\mathrm{l}^{+}$; Fig. 1), and the pac site at the $5^{\prime}$ end of each segment is instrumental for the recognition of a particular segment (Gottlieb et al. 1994; Pirttimaa and Bamford 2000; Qiao et al. 2003). The packaging initiates from the $5^{\prime}$-end of the ssRNA molecules (Qiao et al. 1995). When the last segment is packaged, replication takes place inside the capsid by the $\mathrm{P} 2$ polymerase (Frilander et al. 1995; Poranen and Bamford 1999). After completion of the dsRNA synthesis, the particles initiate transcription (Poranen and Bamford 1999), which leads to the extrusion of the produced $(+)$ strands from the particle.

The packaging of the $\phi 6$ genome is associated with conformational changes in the capsid (Butcher et al. 1997; Nemecek et al. 2011). A model proposes that the pac sequence of the $\mathrm{s}^{+}$ segment binds to the outer surface of the PC and is packaged by the $\mathrm{P} 4$ motor. The subsequent structural transition exposes the $\mathrm{m}^{+}$segment binding sites and hides the binding sites for $\mathrm{s}^{+}$to ensure packaging of correct segments. After the $\mathrm{m}^{+}$ segment is packaged, further expansion exposes the binding sites for $\mathrm{l}^{+}$(Mindich 1999; Nemecek et al. 2011). After packaging $\mathrm{l}^{+}$, the final capsid conformation is reached and the minus-strand synthesis (RNA replication) by P2 is activated (Mindich 1999). This model suggests the existence of at least two intermediate states of the expanding PC (Nemecek et al. 2011). The initial energy barrier for the expansion was proposed to be low and it was suggested that the moderate pressure from the packaged $\mathrm{s}^{+}$segment might trigger the expansion (Nemecek et al. 2011). Alternatively, the trigger can be the interaction of $\mathrm{s}^{+}$with the P1 shell either before packaging (via the pac site) or after packaging from the inside (Nemecek et al. 2011), or even NTP hydrolysis by P4 (Huiskonen et al. 2006). To accommodate the full genome, the internal volume of the PC needs to increase by $140 \%-$ 150\% (Huiskonen et al. 2006; Nemecek et al. 2011). According to recent data, the expansion of the PC to the first intermediate state (after packaging $\mathrm{s}^{+}$) increases the volume by $112 \%$ and to the second intermediate state (after packaging $\mathrm{s}^{+}$and $\mathrm{m}^{+}$) by $136 \%$ (Nemecek et al. 2011). 
The packaging process of $\phi 6$ was estimated to be relatively slow (33 nt/sec) (Frilander and Bamford 1995) compared to the measured genome packaging of the dsDNA bacteriophages (from $700 \mathrm{bp} / \mathrm{sec}$ for T4, to $200 \mathrm{bp} / \mathrm{sec}$ for $\$ 29$ ) (Fuller et al. 2007a; Rickgauer et al. 2008). The slow packaging of $\phi 6$ likely arises from the requirement to unwind the secondary and tertiary RNA structures during the ssRNA translocation into the capsid. Indeed, the P4s of $\phi 8$ and $\phi 13$ (relatives of $\phi 6$ ) exhibit $5^{\prime}-3^{\prime}$ helicase activity in vitro (Kainov et al. 2003). Furthermore, the central channel of the P4 hexamer of $\phi 12$ and $\phi 6$ can only accommodate single-stranded nucleic acid molecules (Mancini et al. 2004; El Omari et al. 2013). Moreover, the ATPase activity of the P4 in $\phi 8$ and $\phi 12$ is only stimulated by ssRNA (Kainov et al. 2003). This information points to the need of helicase activity simultaneously with the packaging.

In this paper, we measure, for the first time, packaging of ssRNA into a viral PC at a single-molecule level. We use the in vitro packaging system developed for recombinant PCs of $\phi 6$ (Gottlieb et al. 1990) and dual-trap optical tweezers to measure packaging under constant-force feedback (experimental setup in Fig. 2).

The maximum packaging velocity measured in our experimental conditions is $4.62 \mathrm{~nm} / \mathrm{sec}$. We observed intermittent fast and slow packaging phases, the latter of which might reflect the slowing down due to the secondary structures of ssRNA, which need to be opened by P4. The overall slowing of the packaging at the end of the experiment might indicate filling of the central part of the PC, which could initiate the expansion of the PC.

\section{RESULTS}

\section{Force-extension measurement}

To evaluate the folding state of the RNA constructs under the conditions optimized for $\phi 6$ genome packaging, we performed a force-extension measurement on $\phi 6$-specific ssRNA.

Figure 3 shows repeated force-extension measurement of a single $\mathrm{s}^{+}$bio-construct-PC-tether in packaging buffer without ATP. Movable bead was displaced in a linear ramp at $88 \mathrm{~nm} /$ sec to stretch the ssRNA molecule. Data show the opening of ssRNA secondary and/or tertiary structures when subjected to pulling by an external force as previously only described for substantially shorter ssRNA molecules (Liphardt et al. 2001; Wen et al. 2007). The sudden drops in measured force correspond to the extension of the construct. Transition force between the opened and closed state of the $\mathrm{s}^{+}$ssRNA was 6.4$22.7 \mathrm{pN}$ (Fig. 3).

All the subsequent experiments were carried out using clamping force below $5.5 \mathrm{pN}$ (Supplemental Table S1) to keep the folding state of the ssRNA construct approximately the same and to avoid force-induced stalling of the packaging NTPase P4 (stalling force for $\phi 8 \mathrm{P} 4$ is $6 \mathrm{pN}$ [Lísal 2006]).
In the measured range $(1-5.5 \mathrm{pN})$, we observe no significant change in the $\phi 6$ packaging rate as a function of clamping force (Supplemental Fig. S1).

\section{ssRNA packaging time series}

Altogether, 445 tethers were measured in the presence of ATP and 116 tethers without ATP. All these were single tethers where a single ssRNA molecule was connecting the two beads. In a few experiments ( 25 with ATP and 9 without ATP), we observed multiple tether formation (Supplemental Fig. $\mathrm{S} 2 \mathrm{~B})$. The data from these experiments were discarded (see Materials and Methods and Supplemental Fig. S2).

Experiments in the presence of ATP exhibiting a packaging velocity of $0.07 \mathrm{~nm} / \mathrm{sec}$ or faster were considered to indicate packaging action (Supplemental Table S1). The cut-off velocity was selected to this particular value, since the distribution of mean packaging velocities had no significant population
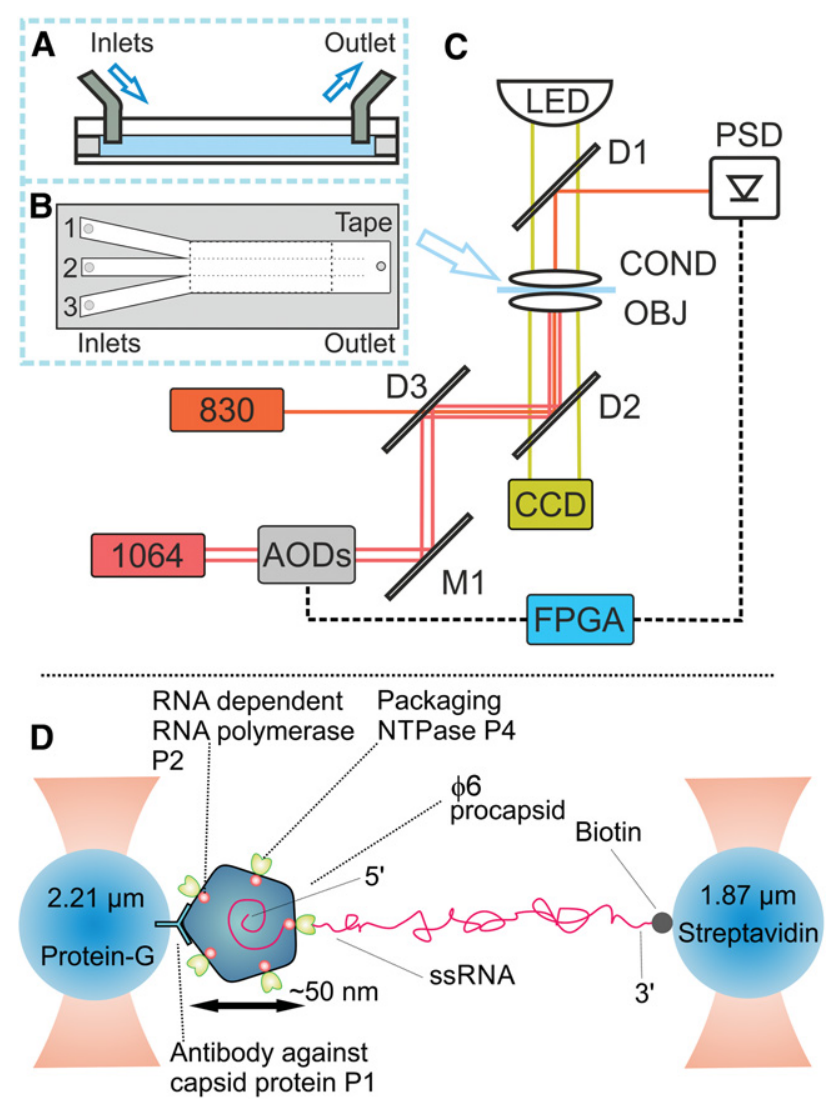

FIGURE 2. Experimental setup. In the inset, $A$ and $B$ show the laminar flow cell from the side and top views, respectively. (C) Simplified schematic of the optical tweezers (OTs) setup; most optical components are omitted. AOD is an acousto-optic deflector, $\mathrm{M}$ is a mirror, $\mathrm{D}$ is a dichroic mirror, CCD is a charge-coupled-device camera, COND and $\mathrm{OBJ}$ are condensor and objective lenses, respectively, PSD is a position-sensitive detector, and FPGA is a field-programmable gate array controller. Numbers in the colored boxes indicate laser wavelengths in nanometers. LED is the light-emitting diode used for imaging illumination. (D) Schematic of the OT assay (not to scale). 


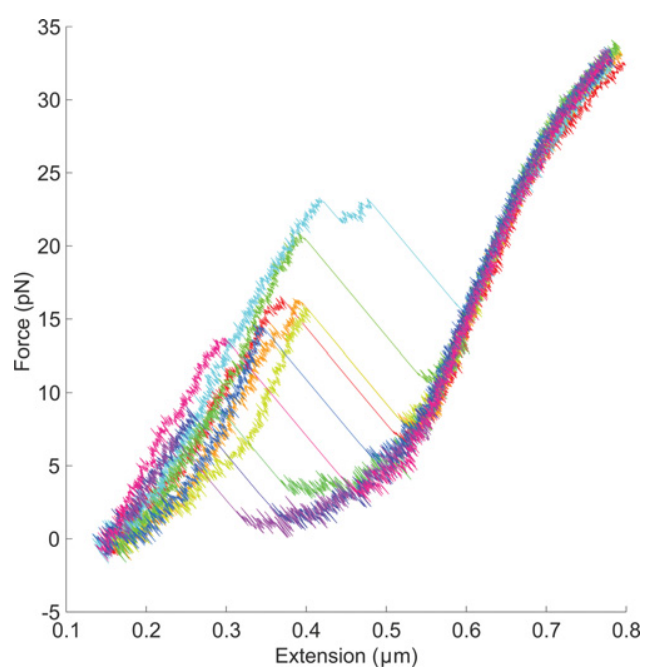

FIGURE 3. Repeated force-extension data of a single s ${ }^{+}$bio ssRNA tether with the $\phi 6$ procapsid. Each trace (color) corresponds to one pull on the tether.

below this cut-off value for the control (no ATP) experiments (data not shown). Of the 445 tethers in the presence of ATP, 24 showed packaging action (see Figs. 4A, 6; Supplemental Figs. S3-S7; Supplemental Table S1), which equals an overall efficiency of packaging experiments of $5.4 \%$. Initial lengths of the measured tethers were $0.26-1.02 \mu \mathrm{m}$ for $\mathrm{s}^{+}$bio and 0.29 $1.48 \mu \mathrm{m}$ for sml ${ }^{+}$bio (Supplemental Table S1), indicating either heterogeneity in RNA construct folds or variation in RNA binding to the capsid. Some tethers exhibited sudden stepwise lengthening at the beginning of the experiment, resulting in a maximum length of $1.20 \mu \mathrm{m}$ for $\mathrm{s}^{+}$bio and 1.51 $\mu \mathrm{m}$ for sml ${ }^{+}$bio (see Figs. 4A, 6; Supplemental Figs. S3-S7; Supplemental Table S1). Figure 4 shows a representative positive experiment and control experiments with ssRNA and
dsDNA, and no ATP. Packaging takes place with a piecewise constant linear velocity. Fast and slow packaging phases can be distinguished, with faster packaging taking place in the beginning of the experiment, close to the $5^{\prime}$ end of the $\mathrm{s}^{+}$ssRNA (Fig. 4A; see Supplemental Fig. S8). Variation in the packaging velocity is apparent in the windowed velocity histogram (Supplemental Fig. S9). The windowed histogram additionally provides rationale for using approximately $-0.4 \mathrm{~nm} / \mathrm{sec}$ as the cut-off value for distinguishing locally fast and slow packaging.

\section{Mean packaging velocities}

Histograms of packaging velocities of positive and control experiments (of Fig. 4) were calculated (Fig. 5). Velocity distributions for the representative experiment show a mean velocity of $-0.32 \pm 0.62 \mathrm{~nm} / \mathrm{sec}(-0.86 \pm 1.68 \mathrm{nt} / \mathrm{sec}$, Fig. $5)$. In the control (no ATP), the tether extension deviates only slightly $(-0.03 \pm 0.58 \mathrm{~nm} / \mathrm{sec})$ due to instrument drift. This value is within the mean instrument drift measured from all control (no ATP) experiments $(-0.048 \pm 0.055$ $\mathrm{nm} / \mathrm{sec}$ ), while the mean packaging velocities calculated from all successful experiments with ATP were 0.07-0.54 $\mathrm{nm} / \mathrm{sec}$ (Supplemental Table S1). Although the overall mean velocity appeared to be relatively low, it was possible to distinguish areas in the original data where the extension changed at a different pace. Figure 6 shows low-pass filtered tether extensions from four of the positive experiments that showed packaging action. Additional packaging traces are shown in Supplemental Figures S3-S7 (for specific conditions of each experiment, see Supplemental Table S1). These data demonstrate the repeatability of the packaging experiments. Packaging velocities for all positive experiments are listed in Supplemental Table S1.
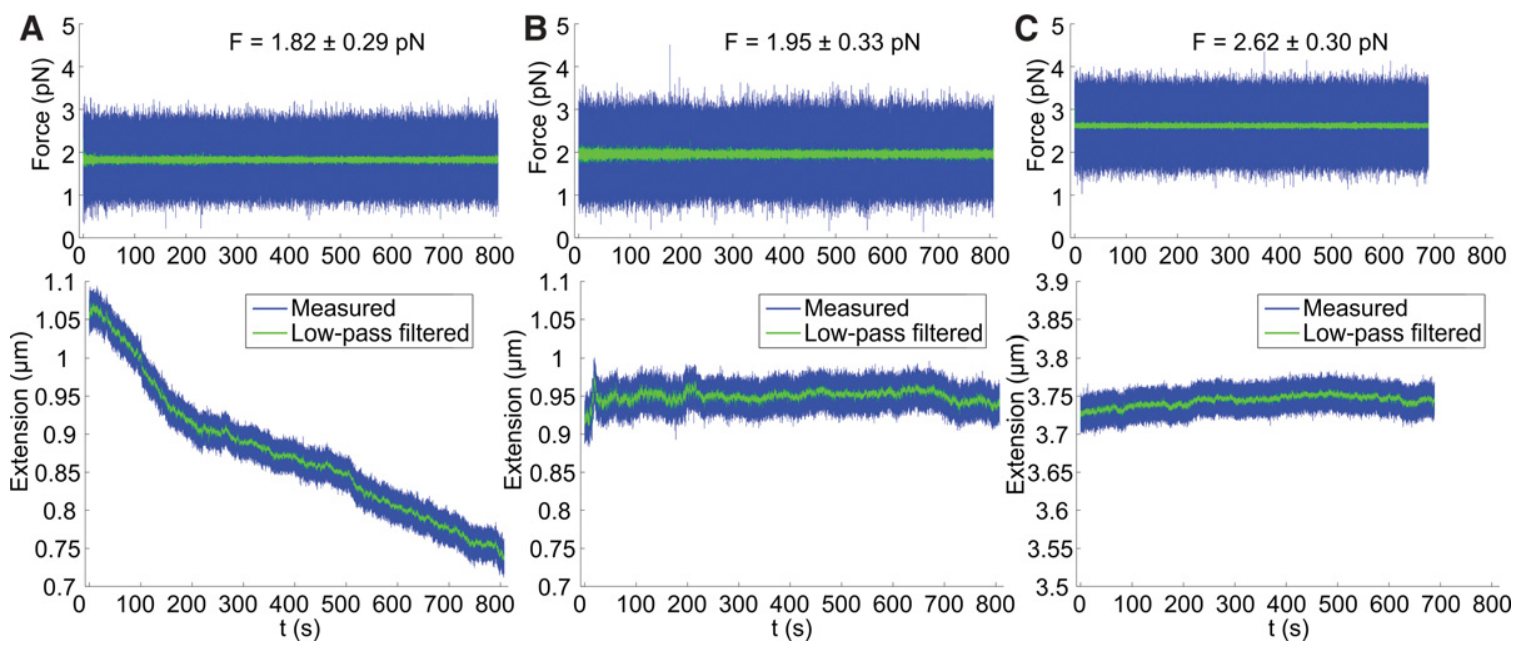

FIGURE 4. Changes in the extension of $\mathrm{s}^{+}$bio ssRNA in packaging reaction as a function of time with $10 \mathrm{mM}$ ATP $(A)$ and without ATP $(B)$. Change of extension of a dsDNA control $(13 \mathrm{~kb})(C)$. Low-pass filtered data $\left(\mathrm{f}_{\mathrm{c}}=10 \mathrm{~Hz}\right)$ are plotted on top of the raw signal. (Upper panel) Force time series, with mean force and standard deviation indicated. (Lower panel) Extension time series. 


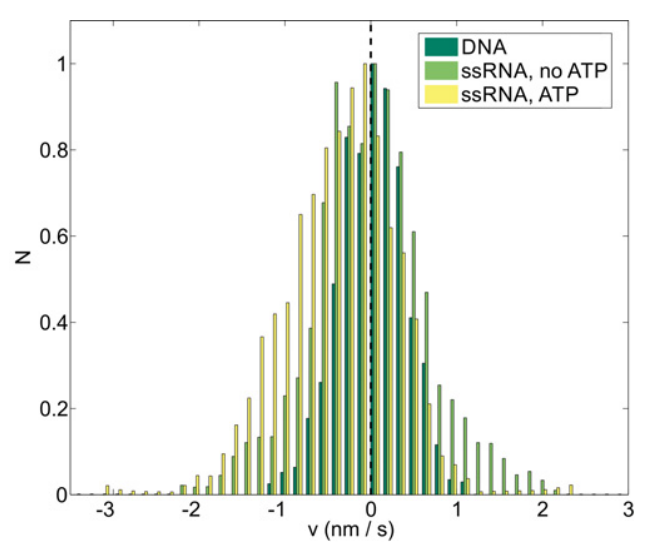

FIGURE 5. Histogram of ssRNA packaging velocities in the presence of $10 \mathrm{mM}$ ATP and without ATP, and the rate of change of tether length of $13 \mathrm{~kb}$ dsDNA control. Histogram count $(N)$ has been normalized to maximum values in each case. Dashed vertical line indicates zero velocity.

\section{Packaging analysis by velocity sections}

Since according to biochemical evidence the packaging of every genomic segment starts from the pac site (Gottlieb et al. 1994), we further analyzed this region of interest (ROI) in the traces representing the packaging of the first $100 \mathrm{~nm}$ of the genomic segment in selected experiments (Fig. 6; Supplemental Figs. S10-S16). All these experiments were carried out in the same buffer conditions and temperature (Supplemental Table S1; tethers 1-8). Figure 7 shows the velocities in separate sections of the ROI of the representative data (from Fig. 4A). The maximum number of nucleotides packaged per section varied from 6 to $25 \mathrm{~nm}$ (corresponding to $\sim 16-68 \mathrm{nt}$ ) (Fig. 7B). The corresponding maximum local velocities were much higher compared to the average velocity per tether and varied from 1.1 to $1.7 \mathrm{~nm} / \mathrm{sec}$, corresponding to $3-4.6 \mathrm{nt} / \mathrm{sec}$ (Fig. 7C). For other tethers, the maximum number of packaged nucleotides reached $40 \mathrm{~nm}(\sim 110 \mathrm{nt})$, whereas the maximum velocity reached $4.62 \mathrm{~nm} / \mathrm{sec}(12.5$ $\mathrm{nt} / \mathrm{sec}$ ) (Supplemental Figs S10-S16).

\section{RNA folding analyses}

Our experimental data on the slow and fast packaging velocity led us to further consider the folding of RNA in the experimental conditions that we used. The secondary structures produced by the mfold program of the genomic $\mathrm{s}^{+}$segment varied remarkably even in the small range $(5 \mathrm{kcal} / \mathrm{mol})$ of folding free energy dG (Supplemental Fig. S17).

To emphasize the complexity of the RNA fold, the 3D structure of the optimal fold of the $\mathrm{s}^{+}$segment is presented in Figure 8A. We further analyzed the secondary structure folds by calculating the length of consecutive paired and unpaired regions starting from the $5^{\prime}$ end of the genomic segment (Fig. 8B). We assumed that the parts of the paired region that become unpaired during packaging (like the part of the stem of the hairpin after the loop) do not refold and therefore remain unpaired (see Materials and Methods). To illustrate the potential difference between individual $\mathrm{s}^{+}$ssRNAs used as substrate in the packaging experiments, the pairing regions for the pac site of the $\mathrm{s}^{+}$segment of the suboptimal mfolds (Supplemental Fig. S17B-F) are presented in Supplemental Figure S18.

\section{DISCUSSION}

Single-stranded RNA molecules are typically highly folded structures, which can be unfolded using forces that exceed the stalling force of viral RNA packaging motors (Fig. 3; Lísal 2006). The folded ssRNA structure presents a major challenge to study viral RNA packaging in vitro at single-molecule resolution. It is difficult to discriminate between the unfolding/refolding of RNA and packaging, since both phenomena change the tether extension. However, since the velocity of the extension change is higher in the experiments with ATP (Fig. 5), the observed change is attributable to packaging.

The initial tether lengths varied (Supplemental Table S1) and also some of the shorter tethers lengthened in a sudden stepwise manner at the beginning of the experiments (Fig. 6; Supplemental Figs. S3-S7). We interpret this phenomenon as the opening of unspecific PC-ssRNA bonds outside the pac site, reflecting unspecific binding of RNA to P1 (Juuti and Bamford 1995).

The overall packaging velocity per tether was relatively low, $\sim 1 \mathrm{nt} / \mathrm{sec}(\sim 0.3 \mathrm{~nm} / \mathrm{sec}$, Supplemental Table S1). We hypothesize that this slowness is due to the secondary structure of ssRNA, which needs to be unfolded by the helicase activity of P4 prior to packaging. Therefore, the measured maximum packaging velocity per section $(\sim 10 \mathrm{nt} / \mathrm{sec})$ seems more credible for the actual RNA translocation. Lísal (2006) reported similar translocation velocities for the purified bacteriophage

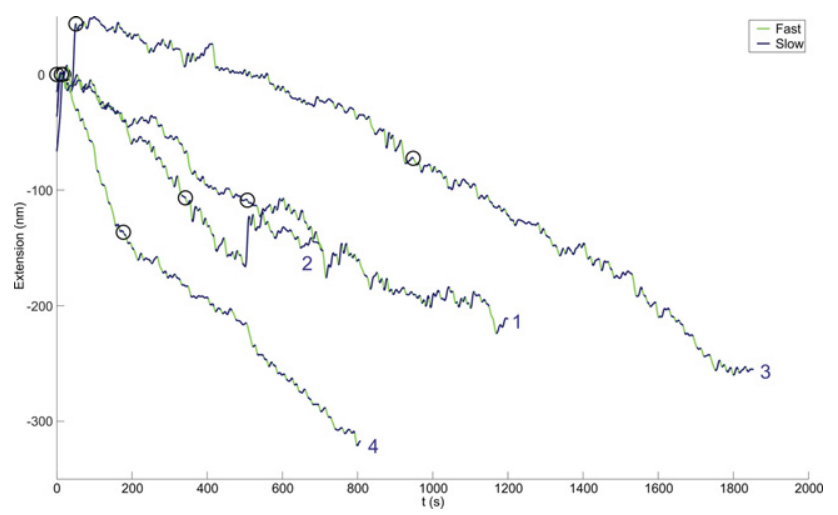

FIGURE 6. Repeatability of packaging time series. Low-pass-filtered $\left(f_{c}=0.1 \mathrm{~Hz}\right)$ signals are plotted with an offset in extension as a function of time for tethers 1-4. Circles mark the beginnings and ends of the regions of interest, i.e., areas that correspond to the proposed packaging site. 


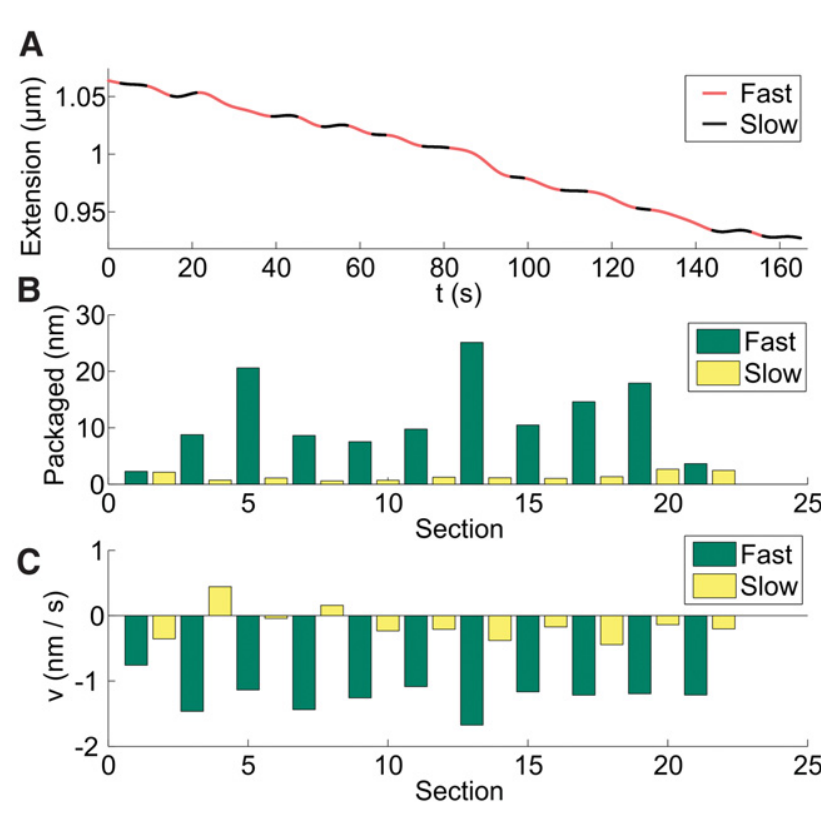

FIGURE 7. Region of interest of representative packaging time series. (A) Low-pass filtered $\left(\mathrm{f}_{\mathrm{c}}=0.1 \mathrm{~Hz}\right)$ ROI of the time series, with windowing into $3 \mathrm{sec}$ sections. (B) Amount of packaged ssRNA per second in nanometers. $(C)$ Mean packaging velocity of each section.

$\phi 8$ packaging NTPase $\mathrm{P} 4$ in two single-molecule experiments using poly $(\mathrm{C})$ as a template.

The pac sites of genomic segments of $\phi 6$ are highly structured (Fig. 8A; Pirttimaa and Bamford 2000). After the opening of small hairpins (tens of nts) at the pac site, there should be patches of tens of nucleotides of ssRNA, which could be packaged without constraints. One could consider that the patches of slow packaging are the pauses due to the opening of hairpins, and that the patches of fast packaging could correspond to unpaired ssRNA that can be packaged without constraints (Fig. 7; Supplemental Figs. S10-S16). Indeed, the folding data of the pac site reveals 3-4 distinct 10-20 nm long unpaired regions (Fig. 8B; Supplemental Fig. S18). Meanwhile the packaging data reveal a similar number of fast packaging regions (Fig. 7B; Supplemental Figs. S10B, S12B, S15B, S16B) of the same length. Also, the paired regions (Fig. 8B; Supplemental Fig. S18), as well as the slow packaging regions (Fig.7B; Supplemental Fig. S10-S16B), are short, rarely longer than $10 \mathrm{~nm}$. Unfortunately, the packaging data are limited by the resolution of our equipment, and small (few nucleotides) changes in extension cannot be resolved.

We emphasize that given our experimental setup and the complexity of the $\mathrm{s}^{+}$RNA folding ( $\sim 188$ hairpins), there may be secondary structures opening at any position in the construct. Furthermore, the existing folding programs take into account only a few conditions (see Materials and Methods) and have limitations in terms of the length of the construct. Therefore, we cannot precisely match the RNA structures to the packaging data.

We considered using an unfoldable ssRNA construct to prove the effect of secondary RNA structures on the packaging rate. However, we encountered three practical problems: (i) the necessity of the pac site for packaging, (ii) the stiffness of the homopolymer, and (iii) early breaking of the tether. This means that all constructs for packaging need to have a structured $300 \mathrm{nt}$ pac site. Furthermore, the unfoldable homopolymer would present an extra challenge when fitting into the limited space of the PC, which would undoubtedly affect the packaging rate. In our experience, many tethers break when $\sim 250 \mathrm{~nm}$ of the ssRNA is packaged (data not shown and Fig. 6), and therefore the experiment might end before a reasonable amount of data is collected. Moreover, using short constructs (less than the diameter of the bead) in optical tweezers is challenging due to an increased likelihood of beads colliding or sticking together.

Our experiments show that packaging of $\phi 6$ at the singlemolecule level is slower than estimated (33 nt/sec) from bulk experiments (Frilander and Bamford 1995). It has been reported for dsDNA bacteriophages that single-molecule
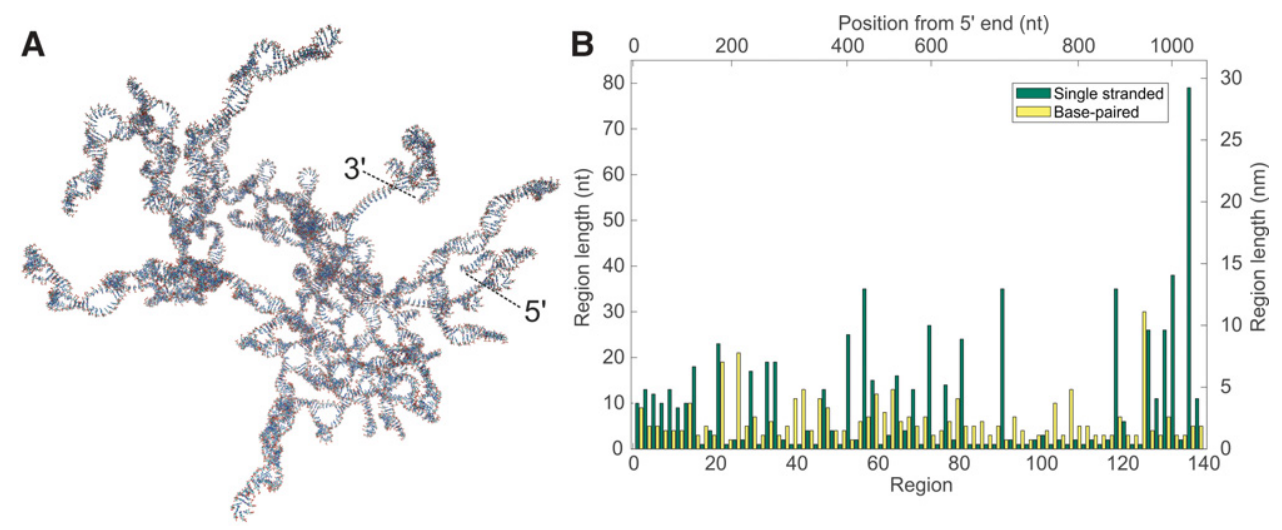

FIGURE 8. (A) Computational 3D structure of $\mathrm{s}^{+}$segment based on optimal mfold-calculated fold. Base-pairing of the first $400 \mathrm{~nm}$ of $\mathrm{s}^{+}$-segment calculated from the optimal mfold structure $(B)$. Subsequent single-stranded and paired ssRNA regions are plotted from the $5^{\prime}$-end. The cumulative number of nucleotides is presented above the graph. 
packaging experiments usually yield a wide distribution of velocity results (Fuller et al. 2007a; Chemla and Smith 2012), and that the highest velocities are rare. Therefore, perhaps the highest packaging velocities due to the sampling limitations of the employed method were undetected. It should also be noted that the experimental conditions in bulk and in optical tweezers are widely different. Even simple conditions like buffer components are difficult to optimize and reproduce. At the single-molecule level, the local ion or nucleotide concentrations around one tether are different than in bulk experiments, due to molecular crowding. This may account for the discrepancy between estimation and measurement.

The packaging motors of dsDNA phages are much faster than the $\phi 6$ one (e.g.,T4 packages at $\sim 700 \mathrm{bp} / \mathrm{sec}, \lambda$ packages at $590 \mathrm{bp} / \mathrm{sec}$, and $\phi 29$ packages at $200 \mathrm{bp} / \mathrm{sec}$ ) (Fuller et al. 2007a,b; Rickgauer et al. 2008). In this case, translocating dsDNA has no structures that need to be opened. To our knowledge, ssRNA packaging at single-molecule resolution in optical tweezers has not been measured previously and therefore there is no comparable data available.

Recently, replication by the $\mathrm{P} 2$ polymerase of $\phi 6$ was investigated using multiplexed magnetic tweezers and an average elongation velocity of $20 \mathrm{nt} / \mathrm{sec}$ was measured (Dulin et al. 2015). The elongation was interrupted by pauses lasting 1 sec to 1000 sec even though P2 was operating on a dsRNA template. As a comparison, the T7 RNA polymerase velocity is 40-400 nt/sec (Skinner et al. 2004; Kim and Larson 2007). It appears that all key enzymatic reactions by $\phi 6$ are slower compared to those of dsDNA phages.

The idea that virus packaging velocity is negatively proportional to genome length is in accordance with the present case (Fuller et al. 2007a; Chemla and Smith 2012). dsDNA bacteriophages with long genomes $(\mathrm{T} 4, \lambda)$ (Chemla and Smith 2012) have to package their genomes quickly in order to complete the infection cycle in $20-30 \mathrm{~min}$. The genome of $\phi 6$ is quite short and the packaging velocity is low; however, the life cycle is considerably longer-80 min (Bamford et al. 1976).

The overall efficiency of an in vitro packaging system is estimated to be $2 \%-5 \%$ (Frilander and Bamford 1995; Poranen et al. 2001; Nemecek et al. 2011). The efficiency in our experiments falls into this range (5\%), despite the additional constraints generated by the optical tweezers experimentation. It has been suggested that the RNA translocation activity of $\phi 6$ P4 depends on association with PC or its components (Kainov et al. 2003). Therefore, it is likely that the packaging inefficiency is due to the missing components possibly lost/ dislocated during purification. Nemecek et al. (2010) reported that $\mathrm{P} 4$ does displace/dislocate during PC purification and storage, leaving predominantly either five or one $\mathrm{P} 4$ hexamers per PC. In this case, the in vitro packaging efficiency at single-molecule resolution would be considerably decreased. Also, particles that have less $\mathrm{P} 4$ (on average only one P4 hexamer) are expanded and do not recognize the $\mathrm{s}^{+}$segment for packaging (Sun et al. 2013), further decreasing the chances of successful experiments.
The original data show slowing down of the packaging at $\sim 200-300$ sec (Fig. 4). In dsDNA bacteriophages, slowing down of the packaging due to filling of the capsid is widely reported (Smith et al. 2001; Fuller et al. 2007b; Rickgauer et al. 2008). In the case of $\phi 6$, capsid filling is unlikely, since PC goes through at least three stages of conformational changes before it reaches the size of the mature PC (Nemecek et al. 2011), and we only study packaging of the small segment. However, it has been suggested that packaging of the $\mathrm{s}^{+}$segment and the subsequent pressure in the PC generated by the packaged RNA can cause the conformational change of the capsid (Nemecek et al. 2011). Our calculations indicate that $\sim 250 \mathrm{~nm}$ of ssRNA $\left(\sim 1 / 4\right.$ of s$\left.^{+}\right)$would fill the space between the recessed fivefold vertices of the PC (see Supplemental Material for the estimation of packaged ssRNA dimensions). It is possible that the packaging process slows down before the PC expansion to the first intermediate state. We believe that this $78 \%$ expansion of the PC (Nemecek et al. 2011) might affect the bond between the P1 and the antibody against it. It is possible that this could break the tether, subsequently ending the experiment.

\section{MATERIALS AND METHODS}

\section{Construct preparation}

RNA constructs $\mathrm{s}^{+}$bio and $\mathrm{sml}^{+}$bio were prepared by biotinylation of (+) sense ssRNA copies of the bacteriophage $\phi 6$ genome segment $S$ and a construct containing all three genome segments joined together (SML). Preparation of synthetic $\mathrm{s}^{+}$and $\mathrm{sml}^{+}$ssRNA was done by run-off transcription in vitro with T7 RNA polymerase, resulting in 2948-nt- and 13,385-nt-long constructs (Makeyev and Bamford 2000b). $\phi 6$ S-segment and SML construct-specific templates for T7 transcription were prepared by PCR amplification from the plasmids pLM659 and pLM1809, respectively (Gottlieb et al. 1992b; Qiao et al. 1997). Biotinylation of the ssRNA constructs was done essentially as described in Rosemeyer et al. (1995) by using Biotin11-dUTP (Thermo Scientific), and dATP (Thermo Scientific) in a molar ratio of 1:9, Terminal Deoxynucleotidyl Transferase (Thermo Scientific), and buffer provided by the manufacturer.

Preparation of the dsDNA control construct was done by restriction digestion of the pTARBAC6 plasmid (Osoegawa et al. 2007) by PacI (NEB) and subsequent biotinylation with Bio-11-dUTP (Thermo Scientific) using terminal deoxynucleotidyl transferase (Thermo Scientific).

\section{Procapsid preparation}

Recombinant wild-type PCs were produced and isolated as in Frilander and Bamford (1995) and Pirttimaa et al. (2002). The Escherichia coli strain JM109 (Yanisch-Perron et al. 1985) was used to express PCs from plasmid pLM687 (Mindich et al. 1994). PCs were purified from the cell lysates using Triton X-114 extraction and centrifugation in a linear sucrose gradient. The light-scattering $\mathrm{PC}$ band was collected, aliquoted, and stored at $-80^{\circ} \mathrm{C}$. Protein concentration was determined by the Coomassie brilliant blue method (Bradford 1976) using bovine serum albumin (BSA) as a standard. 
The protein composition of the PCs was analyzed by gel electrophoresis (SDS-PAGE) using purified $\phi 6$ virions as a control.

\section{In vitro ssRNA packaging assays}

For the packaging experiments, we used three-channel chambers with dimensions of $6 \times 50 \times 0.20 \mathrm{~mm}^{3}$ (Fig. 2A,B; Wallin et al. 2011). Prior to each experiment, the glass coverslips sealing the chamber were treated in $0.5 \%$ Alconox solution as described in Hanhijärvi et al. (2013), and the sample chamber was blocked with TEW buffer (20 mM Tris [pH 8], $1 \mathrm{mM}$ EDTA, $150 \mathrm{mM}$ $\mathrm{NaCl}$, and $0.1 \%$ Tween 20 ) containing $5 \mathrm{mg} / \mathrm{mL}$ BSA. A syringe pump with three $1 \mathrm{~mL}$ syringes introduced beads, RNA, and buffer into the chamber at a rate of $1 \mu \mathrm{L} / \mathrm{min}$.

Each channel of the chamber contained different components in the packaging buffer ( $50 \mathrm{mM}$ Tris [pH 8.9], $2 \mathrm{mM}$ dithiothreitol [DTT], $0.1 \mathrm{mM}$ EDTA, $2.5 \mathrm{mM} \mathrm{MgCl}_{2}, 6 \%$ polyethylene glycol [PEG] [for the molecular weight of the PEG, see Supplemental Table S1], and $80 \mathrm{mM} \mathrm{NH}_{4} \mathrm{Ac}$ [Frilander and Bamford 1995; van Dijk et al. 1995]). Streptavidin-coated (SA) polystyrene beads (1.87 $\mu \mathrm{m}$ diameter, Kisker Biotech) with $\mathrm{s}^{+}$bio or $\mathrm{sml}^{+}$bio construct were in the first channel and protein $\mathrm{G}(\mathrm{PG})$-coated beads $(2.1 \mu \mathrm{m}$ diameter, Kisker Biotech) with antibody against $\phi 6$ packaging ATPase P4 (4S8) (Ojala et al. 1993) or coat protein P1 (1K1) (Olkkonen et al. 1988; see Supplemental Table 1), and purified PCs were in the second channel. The third channel was designated to the force measurement and contained 0 or 1-10 mM ATP in the packaging buffer. All concentrations and ratios (of bead:construct and bead:antibody:PC) were experimentally optimized for each batch of material to produce sufficient tethering efficiency, using fluorescent dyes (Atto488 and Sybr green).

\section{Experimental procedure}

The experiment began by trapping an SA bead with bound $s^{+}$bio in the first channel. The bead was then moved to the second channel, where a PG bead with the antibody-bound PC was trapped. Trapped beads were brought close together to form a tether (Fig. 2D). If no tether was found after a few minutes, the beads were discarded and new beads were fetched. Once a tether was found, the formed dumbbell was moved into the third channel containing buffer with or without ATP. The force clamp was activated and the bead position was measured for $20 \mathrm{~min}$ or until the tether broke spontaneously. If the tether broke in a single step, the tether was deemed single, and the measurement was accepted. If the tether broke in multiple steps, the experiment was discarded as being multiply tethered (Supplemental Fig. S2). The stalling force for recombinant $\mathrm{P} 4$ of $\phi 8$ is $6 \mathrm{pN}$ (Lísal 2006), therefore we kept the clamping force low, $\sim 1-5$ $\mathrm{pN}$, to ensure accurate velocity measurement. This approach has also been used for other phages in optical tweezers experiments (Fuller et al. 2007a; Kottadiel et al. 2012). Typically, experiments were carried out at room temperature (Supplemental Table S1).

\section{DNA control experiment}

For the control experiments with DNA, the streptavidin-coated polystyrene beads were in the first channel. The second channel had the bioDNAbio construct, and the third one contained only packaging buffer. First, two SA beads from the first channel were trapped and moved to the second channel. Beads were moved next to each other and moved through the DNA-containing second channel. In the third channel, beads were moved apart to see if the tether was formed. When the tether was acquired, the experiment was initiated in the third channel.

\section{Optical tweezers experiments}

We used a custom-built optical tweezers instrument with constantforce feedback capability (Wallin et al. 2008, 2011; Ojala et al. 2009). The trap light from an Nd:YAG laser (Compass 1064-4000M, Coherent Santa Clara, operated at $1 \mathrm{~W}$ ) was expanded $(3 \times)$ and directed through a polarizing beam splitter to split the beam in two. One of the resulting polarizations traveled through an acousto-optic deflector (AOD, 45035-3-6.5DEG-1.06-XY, NEOS Technologies Inc). The rest of the light bypassed the AOD. Keplerian telescopes $(1 \times)$ imaged the back focal plane of the objective to the AOD, which facilitated beam-steering at the image plane. The beam that bypassed the AOD resulted in a stationary trap. Finally, trap light was expanded to overfill the back aperture of the objective (CFI Apo TIRF 100X oil immersion, $\mathrm{NA}=1.49$, Nikon Instruments Inc.), which resulted in a tight focus at the image plane.

The position of a trapped bead was measured using back-focalplane interferometry. A $830 \mathrm{~nm}$ diode laser (DL5032-001, Thorlabs Newton) was used for position detection. Light from the diode was coupled into a polarization maintaining fiber (PMF). Output from the PMF was directed to the optical path of the trap light by a dichroic mirror. Finally the microscope objective focused the detection laser onto the trapped bead. Forward-scattered and unperturbed detection light from the trapped bead was collected with the microscope condenser and imaged by a position sensitive detector placed at a conjugate of the back focal plane of the condenser. Position data were digitized with a PCI DAQ-card featuring an integrated FPGA chip (PCI-7833R, National Instruments).

Position detection was calibrated by moving a bead with the AOD-controlled trap over the position of the detection laser spot. A 2D linear function was fit to the linear regime of the detector to determine position sensitivity (in micrometers per volt).

The force measurement was calibrated by recording the Brownian motion of a trapped bead at full sampling rate $(200 \mathrm{kHz})$. The trap stiffness (in piconewtons/micrometer) was calculated by fitting a Lorentzian function to the power spectrum of the recorded position (Wallin et al. 2008).

The force was held constant by PID control. In a typical experiment, a tethered RNA molecule was held between two trapped beads. The position of the stationary bead was measured with the detector laser, while a second bead was steered with the AOD. The tether force measured at the stationary bead changes if the length of the RNA molecule is altered. Therefore, the force can be held constant if the length change is compensated by moving the steerable bead with the PID feedback loop (Wallin et al. 2011). In the experiments described here, we used integral control, with a nondimensional gain constant of $2^{-4}$.

\section{Data analysis}

Tether extension and force extension curves were measured as described in Ojala et al. (2009). The observed tether extension can 
be written as

$$
x(t)=L_{\mathrm{RNA}, \text { fold }}(t)+v_{P 4}(t) t^{\prime}+d_{\text {capsid }}(t),
$$

where $x$ is the measured tether extension at time $t, L_{\mathrm{RNA} \text {,fold }}$ is the length of the folded RNA outside the PC, $v_{P 4}$ is the instantaneous packaging velocity of NTPase $\mathrm{P} 4$, and $d_{\text {capsid }}$ is the effective diameter of the PC. $L_{\mathrm{RNA} \text {,fold }}$ includes the contribution from any possible opening of secondary structure. Assuming no sudden unfolding of the RNA secondary structure and that capsid deformation is negligible, the packaging velocity can be calculated from the time derivative of the tether extension. In Equation 1, negative velocity values indicate net packaging.

Direct numerical differentiation is impractical with noisy raw data. This problem was overcome by low-pass filtering of the extension signal with a zero-phase 12th order Butterworth filter featuring a $0.1 \mathrm{~Hz}$ corner frequency. Filtering was done with MATLAB's signal processing toolbox. After low-pass filtering, the velocity of the tether extension was calculated using five-point numerical differentiation (Abramowitz and Stegun 1964). The calculated velocities were windowed into 3-sec-long sections. These sections were classified as "fast" in terms of packaging if the mean extension velocity in a section was below or equal to $-0.4 \mathrm{~nm} / \mathrm{sec}$ (absolute value below 0.4 $\mathrm{nm} / \mathrm{sec}$ in the negative direction). Sections with mean velocities above $-0.4 \mathrm{~nm} / \mathrm{sec}$ were classified as "slow." During "slow" sections, the secondary structure of the tethered RNA could unfold, which would appear as positive extension velocity. If multiple consecutive sections were classified as either "fast" or "slow," the total section length was an integer multiple of the window length. Packaging velocity histograms were calculated from the mean velocities obtained from the low-pass filtered extension data.

A conversion factor of $0.37 \mathrm{~nm} / \mathrm{nt}$ was used for the estimation of construct length in nucleotides. This number corresponds to the average rise per nucleotide in unstressed homopolymeric ssRNA (Seol et al. 2007).

\section{RNA folding analyses}

Secondary structure prediction was done using mfold 3.6 (Mathews et al. 1999; Zuker et al. 1999), using external conditions corresponding to those in our single-molecule experiments (monovalent salt concentration $80 \mathrm{mM}$, divalent salt concentration $2.5 \mathrm{mM}, T=$ $25^{\circ} \mathrm{C}$ ). The $3 \mathrm{D}$ structure of the folded RNA was calculated using the RNA2D3D software from the STRUCTURELAB package (Shapiro and Kasprzak 1996; Martinez et al. 2008). The VMD package (http://www.ks.uiuc.edu/Research/vmd/) was used to visualize the 3D structure (Humphrey et al. 1996).

The predicted secondary structures were used to calculate estimates for paired and unpaired RNA regions encountered by the packaging motor. Packaging region analysis was done using a MATLAB script. Single-stranded and base-paired regions of the folded RNA were sequentially analyzed by recording their order and lengths starting from the $5^{\prime}$ end. When encountering a base paired stem, the first half of the stem was marked as base paired. When the loop and the (complementary) second half of a stem were encountered, they were marked as single-stranded. We assumed that during packaging the $\mathrm{P} 4$ motor unwinds the base-paired region of the first half of the stem and leaves the other half singlestranded. It was presumed that the single-stranded second half would not fold onto itself during the process.

\section{SUPPLEMENTAL MATERIAL}

Supplemental material is available for this article.

\section{ACKNOWLEDGMENTS}

This study was supported by the Graduate School of Chemical Sensors and Microanalytical systems (CHEMSEM to K.J.H.), Ruth and Nils-Erik Stenbäck's foundation (to K.J.H.), the Sigrid Jusélius foundation (to M.M.P. and D.H.B), and the Academy of Finland (grants 283072 and 255342 to D.H.B. and grants 283192, 250113, and 272507 to M.M.P.). The authors also acknowledge the support of employees and use of the experimental resources of Instruct as well as the Academy of Finland (grant 272853) and the University of Helsinki for support to EU ESFRI Instruct Centre for Virus Production (ICVIR) used in this study.

Received May 12, 2016; accepted October 27, 2016.

\section{REFERENCES}

Abramowitz M, Stegun IA. 1964. Handbook of mathematical functions: with formulas, graphs, and mathematical tables. Courier Corporation, MA.

Baines JD, Weller SK. 2005. Cleavage and packaging of herpes simplex virus 1 DNA. In Viral genome packaging machines: genetics, structure, and mechanism, pp. 135-150. Springer, NY.

Bamford DH, Palva ET, Lounatmaa K. 1976. Ultrastructure and life cycle of the lipid-containing bacteriophage $\phi 6 . J$ Gen Virol 32: 249-259.

Bradford MM. 1976. A rapid and sensitive method for the quantitation of microgram quantities of protein utilizing the principle of proteindye binding. Anal Biochem 72: 248-254.

Butcher SJ, Dokland T, Ojala PM, Bamford DH, Fuller SD. 1997. Intermediates in the assembly pathway of the double-stranded RNA virus $\phi 6 . E M B O J$ 16: 4477-4487.

Butcher SJ, Grimes JM, Makeyev EV, Bamford DH, Stuart DI. 2001. A mechanism for initiating RNA-dependent RNA polymerization. Nature 410: 235-240.

Chemla YR, Smith DE. 2012. Single-molecule studies of viral DNA packaging. In Viral molecular machines, pp. 549-584. Springer, NY.

de Haas F, Paatero AO, Mindich L, Bamford DH, Fuller SD. 1999. A symmetry mismatch at the site of RNA packaging in the polymerase complex of dsRNA bacteriophage $\phi 6$. J Mol Biol 294: 357-372.

Dulin D, Vilfan ID, Berghuis BA, Hage S, Bamford DH, Poranen MM, Depken M, Dekker NH. 2015. Elongation-competent pauses govern the fidelity of a viral RNA-dependent RNA polymerase. Cell Rep 10: 983-992.

El Omari K, Meier C, Kainov D, Sutton G, Grimes JM, Poranen MM, Bamford DH, Tuma R, Stuart DI, Mancini EJ. 2013. Tracking in atomic detail the functional specializations in viral RecA helicases that occur during evolution. Nucleic Acids Res 41: 9396-9410.

Frilander M, Bamford DH. 1995. In vitro packaging of the single-stranded RNA genomic precursors of the segmented double-stranded RNA bacteriophage $\phi 6$ : the three segments modulate each other's packaging efficiency. J Mol Biol 246: 418-428.

Frilander M, Poranen M, Bamford DH. 1995. The large genome segment of dsRNA bacteriophage $\phi 6$ is the key regulator in the in vitro minus and plus strand synthesis. RNA 1: 510-518.

Fuller DN, Raymer DM, Kottadiel VI, Rao VB, Smith DE. 2007a. Single phage T4 DNA packaging motors exhibit large force generation, high velocity, and dynamic variability. Proc Natl Acad Sci 104: $16868-16873$.

Fuller DN, Raymer DM, Rickgauer JP, Robertson RM, Catalano CE, Anderson DL, Grimes S, Smith DE. 2007b. Measurements of single 
DNA molecule packaging dynamics in bacteriophage $\lambda$ reveal high forces, high motor processivity, and capsid transformations. J Mol Biol 373: 1113-1122.

Gottlieb P, Strassman J, Qiao X, Frucht A, Mindich L. 1990. In vitro replication, packaging, and transcription of the segmented doublestranded RNA genome of bacteriophage $\phi 6$ : studies with procapsids assembled from plasmid-encoded proteins. J Bacteriol 172: 5774-5782.

Gottlieb P, Strassman J, Mindich L. 1992a. Protein P4 of the bacteriophage $\phi 6$ procapsid has a nucleoside triphosphate-binding site with associated nucleoside triphosphate phosphohydrolase activity. J Virol 66: 6220-6222.

Gottlieb P, Strassman J, Qiao X, Frilander M, Frucht A, Mindich L. 1992b. In vitro packaging and replication of individual genomic segments of bacteriophage $\phi 6$ RNA. J Virol 66: 2611-2616.

Gottlieb P, Qiao X, Strassman J, Frilander M, Mindich L. 1994. Identification of the packaging regions within the genomic RNA segments of bacteriophage $\phi 6$. Virology 200: 42-47.

Hanhijärvi K, Ziedaite G, Pietilä M, Hæggström E, Bamford DH. 2013. DNA ejection from an archaeal virus-a single-molecule approach. Biophys J 104: 2264-2272.

Hendrix RW. 1978. Symmetry mismatch and DNA packaging in large bacteriophages. Proc Natl Acad Sci 75: 4779-4783.

Huiskonen JT, de Haas F, Bubeck D, Bamford DH, Fuller SD, Butcher SJ. 2006. Structure of the bacteriophage $\phi 6$ nucleocapsid suggests a mechanism for sequential RNA packaging. Structure 14: 1039-1048.

Huiskonen JT, Jäälinoja HT, Briggs JA, Fuller SD, Butcher SJ. 2007. Structure of a hexameric RNA packaging motor in a viral polymerase complex. J Struct Biol 158: 156-164.

Humphrey W, Dalke A, Schulten K. 1996. VMD: visual molecular dynamics. J Mol Graphics 14: 33-38.

Ilca SL, Kotecha A, Sun X, Poranen MM, Stuart DI, Huiskonen JT. 2015. Localized reconstruction of subunits from electron cryomicroscopy images of macromolecular complexes. Nat Commun 6: 1-8.

Juuti JT, Bamford DH. 1995. RNA binding, packaging and polymerase activities of the different incomplete polymerase complex particles of dsRNA bacteriophage $\phi 6 . J$ Mol Biol 249: 545-554.

Juuti JT, Bamford DH. 1997. Protein P7 of phage $\phi 6$ RNA polymerase complex, acquiring of RNA packaging activity by in vitro assembly of the purified protein onto deficient particles. J Mol Biol 266: 891-900.

Kainov DE, Pirttimaa M, Tuma R, Butcher SJ, Thomas GJ, Bamford DH, Makeyev EV. 2003. RNA packaging device of double-stranded RNA bacteriophages, possibly as simple as hexamer of P4 protein. J Biol Chem 278: 48084-48091.

Kainov DE, Lísal J, Bamford DH, Tuma R. 2004. Packaging motor from double-stranded RNA bacteriophage $\phi 12$ acts as an obligatory passive conduit during transcription. Nucleic Acids Res 32: 3515-3521.

Kainov D, Tuma R, Mancini E. 2006. Hexameric molecular motors: P4 packaging ATPase unravels the mechanism. Cell Mol Life Sci 63: 1095-1105.

Kainov DE, Mancini EJ, Telenius J, Lísal J, Grimes JM, Bamford DH, Stuart DI, Tuma R. 2008. Structural basis of mechanochemical coupling in a hexameric molecular motor. J Biol Chem 283: 3607-3617.

Kim JH, Larson RG. 2007. Single-molecule analysis of 1D diffusion and transcription elongation of T7 RNA polymerase along individual stretched DNA molecules. Nucleic Acids Res 35: 3848-3858.

Kottadiel VI, Rao VB, Chemla YR. 2012. The dynamic pause-unpackaging state, an off-translocation recovery state of a DNA packaging motor from bacteriophage T4. Proc Natl Acad Sci 109: 20000-20005.

Liphardt J, Onoa B, Smith SB, Tinoco I, Bustamante C. 2001. Reversible unfolding of single RNA molecules by mechanical force. Science 292: 733-737.

Lísal J. 2006. "Mechanism of RNA translocation by a viral packaging motor." PhD thesis, University of Helsinki, Finland.

Lísal J, Tuma R. 2005. Cooperative mechanism of RNA packaging motor. J Biol Chem 280: 23157-23164.

Lísal J, Lam TT, Kainov DE, Emmett MR, Marshall AG, Tuma R. 2005. Functional visualization of viral molecular motor by hydrogen-deu- terium exchange reveals transient states. Nat Struct Mol Biol 12: 460-466.

Makeyev EV, Bamford DH. 2000a. The polymerase subunit of a dsRNA virus plays a central role in the regulation of viral RNA metabolism. EMBO J 19: 6275-6284.

Makeyev EV, Bamford DH. 2000b. Replicase activity of purified recombinant protein $\mathrm{P} 2$ of double-stranded RNA bacteriophage $\phi 6$. EMBO J 19: 124-133.

Mancini EJ, Tuma R. 2012. Mechanism of RNA packaging motor. In Viral molecular machines, pp. 609-629. Springer, NY.

Mancini EJ, Kainov DE, Grimes JM, Tuma R, Bamford DH, Stuart DI. 2004. Atomic snapshots of an RNA packaging motor reveal conformational changes linking ATP hydrolysis to RNA translocation. Cell 118: 743-755.

Martinez HM, Maizel JV Jr, Shapiro BA. 2008. RNA2D3D: a program for generating, viewing, and comparing 3-dimensional models of RNA. J Biomol Struct Dyn 25: 669-683.

Mathews DH, Sabina J, Zuker M, Turner DH. 1999. Expanded sequence dependence of thermodynamic parameters improves prediction of RNA secondary structure. J Mol Biol 288: 911-940.

Meier C, Mancini EJ, Bamford DH, Walsh MA, Stuart DI, Grimes JM. 2005. Overcoming the false-minima problem in direct methods: structure determination of the packaging enzyme P4 from bacteriophage $\phi 13$. Acta Crystallogr Sect D Biol Crystallogr 61: 1238-1244.

Mindich L. 1999. Precise packaging of the three genomic segments of the double-stranded-RNA bacteriophage $\$ 6$. Microbiol Mol Biol Rev 63: 149-160.

Mindich L, Qiao X, Onodera S, Gottlieb P, Frilander M. 1994. RNA structural requirements for stability and minus-strand synthesis in the dsRNA bacteriophage $\phi 6$. Virology 202: 258-263.

Nemecek D, Heymann JB, Qiao J, Mindich L, Steven AC. 2010. Cryoelectron tomography of bacteriophage $\phi 6$ procapsids shows random occupancy of the binding sites for RNA polymerase and packaging NTPase. J Struct Biol 171: 389-396.

Nemecek D, Cheng N, Qiao J, Mindich L, Steven AC, Heymann JB. 2011. Stepwise expansion of the bacteriophage $\phi 6$ procapsid: possible packaging intermediates. J Mol Biol 414: 260-271.

Nemecek D, Qiao J, Mindich L, Steven AC, Heymann JB. 2012. Packaging accessory protein P7 and polymerase P2 have mutually occluding binding sites inside the bacteriophage $\$ 6$ procapsid. $J$ Virol 86: 11616-11624.

Ojala PM, Juuti JT, Bamford DH. 1993. Protein P4 of double-stranded RNA bacteriophage $\phi 6$ is accessible on the nucleocapsid surface: epitope mapping and orientation of the protein. J Virol 67: 2879-2886.

Ojala H, Korsbäck A, Wallin AE, Hæggström E. 2009. Optical position clamping with predictive control. Appl Phys Lett 95: 181104.

Olkkonen VM, Bamford DH. 1987. The nucleocapsid of the lipid-containing double-stranded RNA bacteriophage $\phi 6$ contains a protein skeleton consisting of a single polypeptide species. J Virol 61: 2362-2367.

Olkkonen VM, Pekkala PM, Bamford DH. 1988. Monoclonal antibodies to the major structural proteins of bacteriophage $\phi 6$. Virology 165: 317-320.

Osoegawa K, Vessere GM, Shu CL, Hoskins RA, Abad JP, de Pablos B, Villasante A, de Jong PJ. 2007. BAC clones generated from sheared DNA. Genomics 89: 291-299.

Ostapchuk P, Hearing P. 2005. Control of adenovirus packaging. J Cell Biochem 96: 25-35.

Pirttimaa MJ, Bamford DH. 2000. RNA secondary structures of the bacteriophage $\phi 6$ packaging regions. RNA 6: $880-889$.

Pirttimaa MJ, Bamford DH. 2005. Nucleic acid packaging of RNA viruses. Rev Cell Biol Mol Med.

Pirttimaa MJ, Paatero AO, Frilander MJ, Bamford DH. 2002. Nonspecific nucleoside triphosphatase P4 of double-stranded RNA bacteriophage $\phi 6$ is required for single-stranded RNA packaging and transcription. J Virol 76: 10122-10127.

Poranen MM, Bamford DH. 1999. Packaging and replication regulation revealed by chimeric genome segments of double-stranded RNA bacteriophage $\phi 6$. RNA 5: 446-454. 
Poranen MM, Bamford DH. 2012. Assembly of large icosahedral double-stranded RNA viruses. In Viral molecular machines, pp. 379-402. Springer, NY.

Poranen MM, Paatero AO, Tuma R, Bamford DH. 2001. Self-assembly of a viral molecular machine from purified protein and RNA constituents. Mol Cell 7: 845-854.

Qiao X, Qiao J, Mindich L. 1995. Interference with bacteriophage $\phi 6$ genomic RNA packaging by hairpin structures. J Virol 69: 55025505.

Qiao X, Qiao J, Mindich L. 1997. Stoichiometric packaging of the three genomic segments of double-stranded RNA bacteriophage $\$ 6$. Proc Natl Acad Sci 94: 4074-4079.

Qiao X, Qiao J, Mindich L. 2003. Analysis of specific binding involved in genomic packaging of the double-stranded-RNA bacteriophage $\phi 6 . J$ Bacteriol 185: 6409-6414.

Rickgauer JP, Fuller DN, Grimes S, Jardine PJ, Anderson DL, Smith DE. 2008. Portal motor velocity and internal force resisting viral DNA packaging in bacteriophage $\phi 29$. Biophys J 94: 159-167.

Rosemeyer V, Laubrock A, Seibl R. 1995. Nonradioactive 3 '-end-labeling of RNA molecules of different lengths by terminal deoxynucleotidyltransferase. Anal Biochem 224: 446-449.

Seol Y, Skinner GM, Visscher K, Buhot A, Halperin A. 2007. Stretching of homopolymeric RNA reveals single-stranded helices and basestacking. Phys Rev Lett 98: 158103.

Shapiro BA, Kasprzak W. 1996. STRUCTURELAB: a heterogeneous bioinformatics system for RNA structure analysis. J Mol Graphics 14: 194-205.

Simpson AA, Tao Y, Leiman PG, Badasso MO, He Y, Jardine PJ, Olson NH, Morais MC, Grimes S, Anderson DL. 2000. Structure of the bacteriophage $\$ 29$ DNA packaging motor. Nature 408: 745-750.

Skinner GM, Baumann CG, Quinn DM, Molloy JE, Hoggett JG. 2004. Promoter binding, initiation, and elongation by bacteriophage T7 RNA polymerase a single-molecule view of the transcription cycle. J Biol Chem 279: 3239-3244.

Smith DE. 2011. Single-molecule studies of viral DNA packaging. Curr Opin Virol 1: 134-141.
Smith DE, Tans SJ, Smith SB, Grimes S, Anderson DL, Bustamante C. 2001 . The bacteriophage $\phi 29$ portal motor can package DNA against a large internal force. Nature 413: 748-752.

Speir JA, Johnson JE. 2012. Nucleic acid packaging in viruses. Curr Opin Struct Biol 22: 65-71.

Sun S, Rao VB, Rossmann MG. 2010. Genome packaging in viruses. Curr Opin Struct Biol 20: 114-120.

Sun X, Bamford DH, Poranen MM. 2012. Probing, by self-assembly, the number of potential binding sites for minor protein subunits in the procapsid of double-stranded RNA bacteriophage $\Phi 6 . J$ Virol 86: 12208-12216.

Sun X, Pirttimaa MJ, Bamford DH, Poranen MM. 2013. Rescue of maturation off-pathway products in the assembly of pseudomonas phage $\phi 6 . J$ Virol 87: 13279-13286.

van Dijk AA, Frilander M, Bamford DH. 1995. Differentiation between minus-and plus-strand synthesis: polymerase activity of dsRNA bacteriophage $\phi 6$ in an in vitro packaging and replication system. Virology 211: 320-323.

Wallin AE, Ojala H, Hæggström E, Tuma R. 2008. Stiffer optical tweezers through real-time feedback control. Appl Phys Lett 92: 224104.

Wallin AE, Ojala H, Ziedaite G, Hæggström E. 2011. Dual-trap optical tweezers with real-time force clamp control. Rev Sci Instrum 82: 083102.

Wen J-D, Manosas M, Li PT, Smith SB, Bustamante C, Ritort F, Tinoco I. 2007. Force unfolding kinetics of RNA using optical tweezers. I. Effects of experimental variables on measured results. Biophys J 92: 2996-3009.

Wright S, Poranen MM, Bamford DH, Stuart DI, Grimes JM. 2012. Noncatalytic ions direct the RNA-dependent RNA polymerase of bacterial double-stranded RNA virus $\phi 6$ from de novo initiation to elongation. J Virol 86: 2837-2849.

Yanisch-Perron C, Vieira J, Messing J. 1985. Improved M13 phage cloning vectors and host strains: nucleotide sequences of the M13mpl8 and pUC19 vectors. Gene 33: 103-119.

Zuker M, Mathews DH, Turner DH. 1999. Algorithms and thermodynamics for RNA secondary structure prediction: a practical guide. In RNA biochemistry and biotechnology, pp. 11-43. Kluwer Academic Publishers, Dordrecht, the Netherlands. 

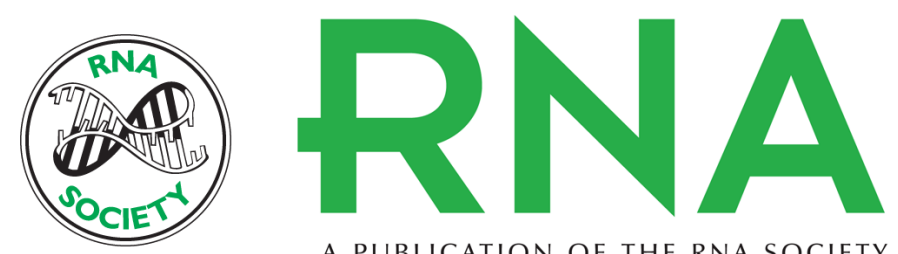

A PUBLICATION OF THE RNA SOCIETY

\section{Single-molecule measurements of viral ssRNA packaging}

Kalle J. Hanhijärvi, Gabija Ziedaite, Dennis H. Bamford, et al.

RNA 2017 23: 119-129 originally published online November 1, 2016

Access the most recent version at doi:10.1261/rna.057471.116

Supplemental Material

References

Creative Commons License

Email Alerting Service
http://rnajournal.cshlp.org/content/suppl/2016/11/01/rna.057471.116.DC1

This article cites 74 articles, 28 of which can be accessed free at: http://rnajournal.cshlp.org/content/23/1/119.full.html\#ref-list-1

This article is distributed exclusively by the RNA Society for the first 12 months after the full-issue publication date (see http://rnajournal.cshlp.org/site/misc/terms.xhtml). After 12 months, it is available under a Creative Commons License (Attribution-NonCommercial 4.0 International), as described at http://creativecommons.org/licenses/by-nc/4.0/.

Receive free email alerts when new articles cite this article - sign up in the box at the top right corner of the article or click here.

To subscribe to $R N A$ go to:

http://rnajournal.cshlp.org/subscriptions 